\title{
ARTIGO
}

d०/ https://doi.org/10.22481/praxis.v15i32.5054

\section{EDUCAÇÃO INCLUSIVA: UMA REFLEXÃO A PARTIR DE NARRATIVAS AUTOBIOGRÁFICAS}

\author{
INCLUSIVE EDUCATION: A REFLECTION FROM AUTOBIOGRAPHICAL \\ NARRATIVES
}

EDUCACIÓN INCLUSIVA: UNA REFLEXIÓN A PARTIR DE NARRATIVAS AUTOBIOGRÁFICAS

Marcos Lucena da Fonseca

Universidade Católica de Pernambuco - Brasil

Maria do Carmo Barbosa de Melo

Universidade de Pernambuco - Brasil

\begin{abstract}
Resumo: O presente texto enfatiza a possibilidade de experiências exitosas desenvolvidas no Instituto Padre Luis Cecchin com crianças e adolescentes considerados em situação de vulnerabilidade social. O eixo da pesquisa esteve centrado na fala de egressos e na devida observação de seus processos formativos. Foi realizado o exercício de escuta e por meio da modalidade metodológica Narrativas Autobiográficas atestamos possibilidades sobre experiências de trabalhos que podemos chamar de Educação Inclusiva, pautada na Educação Não-Formal, cujos princípios defendem oportunidades de convivência e de vivência com equidade para todos. Numa perspectiva humanizante e humanizadora procura-se desenvolver oportunidade de desenvolvimento integral por meio de estratégias, técnicas e práticas educacionais que contemplem e favoreçam uma formação de qualidade, explorando várias dimensões de educação. Entre os autores que defendem esses princípios e que respaldou o presente trabalho destacamos Mantoan (2015), Gohn (2015) e Arroyo (2012).
\end{abstract}

Palavras-chave: Educação. Educação inclusiva. Vulnerabilidade social.

Abstract: The present text emphasizes the possibility of successful experiences developed at the Padre Luis Cecchin Institute with children and adolescents considered to be in a situation of social vulnerability. The focus of the research was centered on the discourse of graduates and the due observation of their formative processes. The listening exercise was carried out and through the methodological modality Autobiographical Narratives we attest possibilities about work experiences that we can call Inclusive Education, based on Non-formal Education, whose principles defend opportunities for coexistence and living with equity for all. From a humanizing and humanizing perspective, we seek to develop an opportunity for integral development through strategies, techniques and educational practices that contemplate and favor a quality education, exploring several dimensions 
of education. Among the authors who defend these principles and who supported the present work we highlight Mantoan (2015), Gohn (2015) and Arroyo (2012).

Keywords: Education. Inclusive education. Social vulnerability.

Resumen: El presente texto enfatiza la posibilidad de experiencias exitosas desarrolladas en el Instituto Padre Luis Cecchin con niños y adolescentes considerados en situación de vulnerabilidad social. El eje de la investigación estuvo centrado en el habla de egresados y en la debida observación de sus procesos formativos. Se realizó el ejercicio de escucha y por medio de la modalidad metodológica Narrativas Autobiográficas atestiguamos posibilidades sobre experiencias de trabajos que podemos llamar Educación Inclusiva, pautada en la Educación No Formal, cuyos principios defienden oportunidades de convivencia y de vivencia con equidad para todos. En una perspectiva humanizadora y humanizadora se busca desarrollar una oportunidad de desarrollo integral a través de estrategias, técnicas y prácticas educativas que contemplen y favorezcan una formación de calidad, explorando varias dimensiones de educación. Entre los autores que defienden estos principios y que respaldó el presente trabajo destacamos Mantoan (2015), Gohn (2015) y Arroyo (2012).

Palabras clave: Educación. Educación inclusiva. La vulnerabilidad social.

\section{Introdução}

O tema referente à Educação Inclusiva, especialmente, tratando-se de crianças e adolescentes em situação de vulnerabilidade social, é alvo necessário de aprofundar, confrontar e relevar a importância da escola, especialmente, à pública como espaço privilegiado de formação com dimensão integral, pela ação dialógica e democrática. $\mathrm{O}$ fazer pedagógico alinhado ao fazer democrático e iluminado pelo princípio humanitário no interior do espaço escolar pode realizar transformações de vidas que ali vão se construindo, no respeito às diferenças e as condições objetivas e subjetivas de cada sujeito.

A literatura tem se esforçado para apontar e analisar a importância da prevenção e intervenção na realidade dos adolescentes e das crianças com vulnerabilidade social na escola. Rizini (1995) diz que “o problema dos meninos (em situação) de rua tem sido debatido internacionalmente como um desafio que demanda urgente solução (...)” (p.13). Os dados apontados pelo Banco Mundial nos anos 90 mostram que 57\% da pobreza nacional atingiam crianças e adolescentes na faixa etária de 0 a 17 anos de idade, "entre os efeitos da pobreza na infância encontram-se a desnutrição e o trabalho infantil, dois fenômenos que, certamente, contribuem para a perpetuação da iniquidade existente.” (UNICEF, 1998, p. 5).

Considerando que a infância é uma fase de vulnerabilidade e dependência, os determinantes vividos e vivenciados no espaço da escola são potencialmente marcantes. Diante desta situação o que podemos e devemos fazer? Como diz DE ALBUQUERQUE 
(2002), a Educação como uma prática social precisa ter como principal função " a "formação do homem e sua realização na sociedade”(p.5). Para Arroyo(2015), precisamos está atentos,

A essas infâncias-adolescências que a sociedade deixa na estrada, às margens de um indigno humano viver. Lições para o pensamento pedagógico, para formação de educadores/as comprometidos com buscas onde essa infância ficou (p. 340).

Entendemos, assim como Arroyo, que esses sujeitos deixados à margem da sociedade evidencia o desafio que a escola precisa enfrentar, lembrando o importante papel que a Educação pode exercer na vida de cada um, se o mesmo tiver oportunidade de ter um processo educativo que lhe promova empoderamento, dignidade e cidadania e, mormente, transformação pessoal com perspectiva de ser um agente de mudança social positiva.

Face à esta realidade, entende-se que urge discussões e ações centradas na Educação Inclusiva e num olhar mais alargado para a Educação Não-Formal como modalidades educativas cabíveis para que tais sujeitos tenham boas perspectivas de mudanças pessoais e, por consequência, sociais, pautando-se naquilo que advoga De Albuquerque(2002), ao compreender a Educação como processo que deve favorecer a democracia, "do saber viver e conviver com as inúmeras diferenças, respeitando-as" ( p.59). Compartilha-se do conceito de Educação de Rodrigues, quando afirma:

A educação é compreendida como um instrumento de formação ampla, de luta pelos direitos, pela cidadania e da emancipação social, preparando as pessoas e a sociedade para responsabilidade de construir, coletivamente, um projeto de inclusão e de qualidade social para o país. (RODRIGUES, 2016, p. 8-9)

Partindo do conceito de Educação acima e ancorado em reflexões como a de Gohn (2015), de Lopes (2015), de Mantoan (2015), de Arroyo (2012), e, sobretudo, a partir de Narrativas Autobiográficas de egressos do Instituto Pe. Luis Cecchin em Limoeiro-PE (IPLC), considerados êxitos sociais1, estruturou-se esse texto.

\section{Metodologia}

O estudo delineado neste artigo traz boas repercussões, no contexto referidos pelas reflexões dos teóricos já citados, especialmente, aos que se referem à resposta, à intervenção e à identificação precoce de problemas que estão bem presentes em nossa realidade.

\footnotetext{
${ }^{1}$ Nosso entendimento de êxito social está baseado no de dignidade humana a partir de Piovesan (2013): direitos à vida, à propriedade privada, à liberdade de pensamento, de expressão, de crença, igualdade formal, à nacionalidade, de participar do governo do seu Estado, podendo votar e ser votado ao trabalho, à educação, à saúde, à previdência social, à moradia, à distribuição de renda, à paz, ao progresso, do consumidor, autodeterminação, entre outros.
} 
O Projeto do Instituto Pe. Luis Cecchin2, de acolhimento a crianças e a adolescentes em situação de vulnerabilidade social, é uma experiência que deve ser estudada, discutida e socializada. Para tal análise, optamos pela abordagem qualitativa, tanto na discussão dos textos teóricos, como para interpretação dos discursos produzidos pelos 14 egressos ouvidos, dos quais 7 foram selecionados, abaixo descrito:

\begin{tabular}{|l|l|l|l|}
\multicolumn{1}{|c|}{ EGRESSOS } & FORMAÇÃO & \multicolumn{2}{c|}{ PROFISSÃO } \\
\hline Homem & Filosofialteologia & Padre & Pároco \\
\hline Idem & MarcenarialE.Médio & Marceneiro & Empregado \\
\hline Idem & Administração & Empresário & Empregador \\
\hline Mulher & Serviço Social & Assistente Social & Empregada \\
\hline Idem & PedagogialHistória & PedagogalProfessora & Vice-gestora \\
\hline Idem & Contabilidade & Bancário & Gerente Regional \\
\hline Idem & Direito & Policial Militar & Servidor Público \\
\hline
\end{tabular}

É relevante dizer que todos os participantes da pesquisa, até hoje, investem em suas respectivas profissões, sempre com progresso no conhecimento profissional que escolheram e, ainda, declaram-se cidadãos éticos. Todos trabalham, inclusive alguns são multiplicadores de empregos e agentes socializadores. Todos se consideram "vencedores", porque conseguiram superar suas respectivas situações de vulnerabilidade social.

A abordagem adotada é qualitativa, tendo por modalidade metodológica "Narrativas Autobiográficas", a partir do que trazem os egressos. Tal modalidade designa a história de vida contada pela pessoa que vivenciou a realidade de acolhimento, de abrigo e de formação. “Tem por objetivo tirar o pesquisador do pedestal de 'dono do saber' e ouvir o que o sujeito tem a dizer por si mesmo. Método histórico, dinâmico e dialético" (SPINDOLA e SANTOS, 2003, p. 121).

\footnotetext{
${ }^{2}$ O Instituto Padre Luis Cecchin existe há 47 anos. Foi fundado pelo Padre Luís Cecchin. Um homem que no passado deu início a reconstrução da história de muitas pessoas. O instituto é uma entidade filantrópica, de caráter beneficente e sem fins lucrativos, fato que é destacado em uma placa na entrada principal do prédio. Desenvolve todas atividades com muito empenho, planejamento, amor, dedicação, clareza, profissionalismo, respeito mútuo. Localizado na Avenida Prof. Rivadávia B. de Paula, 155 - Bairro José Fernandes Salsa, Limoeiro, Pernambuco. Proposta Político Pedagógica: Ver: não se fixar nas aparências, mas adentrar a realidade da pessoa. Inclinar-se: sair de si para colocarse junto ao outro, no mesmo nível. Abandonar o que se é para reconhecer quem é o outro. Sacudir suavemente: ajudar a despertar, não com violência, mas com a suavidade de quem respeita o outro com tudo aquilo que circunda e mesmo numa atitude de silêncio que assegura: "estou aqui com você para o que der e vier". Reconhecer: é saber ultrapassar as defesas que nos distanciam dos outros e reconhecer neles o que têm de mais profundo: são pessoas, filhos de Deus, nossos irmãos. Acolher: é oferecer a oportunidade de olhar a vida a esperança e construir sonhos, na solidariedade de irmãos. Mais informações: https://iplclimoeiro.wordpress.com/nossa-pedagogia/ .
} 
Vale ressaltar aquilo que André (2009) propugna ao apontar que, a partir dos anos de 1990, as pesquisas acadêmicas têm considerado as memórias, lembranças, relatos de vida, biografias, histórias de vida, narrativas memorialísticas e os ensaios autobiográficos como algo importante, com enfoque científico, em que se tem colocado em destaque uma visão de pesquisa centrada no sujeito enquanto produtor de conhecimento.

Outro ponto a chamar atenção é que o método autobiográfico toma corpo e distinguese por ser uma metodologia baseada na narração em que se situa a própria história do sujeito, "tratando-se de uma metodologia de pesquisa e de formação orientada por um projeto de conhecimento coletivo e individual, associado a um processo de formação existencialmente individualizado" (JOSSO, 2004, p.85). Ainda, este método reconhece tanto os saberes formais externos aos sujeitos, quanto os saberes subjetivos e não formalizados que as pessoas transportam consigo, os quais são tecidos nas suas experiências de vida em diferentes contextos socioculturais (DELORY-MOMBERGER, 2008).

Neste contexto, faz-se muito importante a ideia de Nóvoa e Finger (2010), ao defenderem que uma das principais qualidades do método (auto)biográfico está em conceder uma atenção particular aos sujeitos e, assim, o respeito pelos processos pessoais que os formam. Assim, os egressos, hoje considerados por eles e pela sociedade, como sujeitos que possuem e vivem uma vida com dignidade humana, foram entrevistados e estimulados a fazerem suas narrativas de vida enfatizando aquilo que consideram importante e que teve relevância em sua formação como cidadão. As narrativas que foram analisadas, as quais mostram um conteúdo prático, reflexível e flexível, que parece relevante para uma Educação de qualidade e que pretende ser inclusiva, sobretudo quando o público crianças e adolescentes em situação de vulnerabilidade social - CASVS - é fulcro desse artigo..

As narrativas dos egressos foram gravadas e transcritas, e, para a análise dos dados, selecionou-se trechos das narrativas que trazem achados significativos, diante da urgência do problema, isto é, da realidade excludente em que vivem muitas crianças e adolescentes no Brasil. Nas transcrições, para preservar a identidade dos participantes, optamos por substituir os nomes reais dos egressos pelas letras EN, seguido de algarismos arábicos.

\section{A Educação e a Inclusão social}

A partir da Declaração de Salamanca (1994) tem-se o marco da Educação Inclusiva, pois a inclusão passa a fazer parte do processo educacional. Este documento oficial serviu de 
base para os líderes governamentais e não governamentais buscarem formas de resolver o problema social da exclusão. Então, a Declaração parece apontar uma decisão, ou um "norte" emergencial, especialmente, nos países onde a desigualdade é gritante.

No Brasil, a Educação Inclusiva passa a tomar acento a partir da Constituição Federal (1988), do ECA (1990) e da LDB (1996), os quais requerem que a Educação proporcione o desenvolvimento humano na sua plenitude, em condições de liberdade e dignidade, respeitando e valorizando as diferenças (BRASIL, 2013). Considerando os avanços políticos apontados no Brasil, não tem como não recorrer a Foucault para tentar entender porque na realidade avançamos tão pouco nesse sentido. Como bem coloca Veiga (2007),

[...] as forças de que fala Foucault (...) não estão nas mãos de alguns atores ou de algum grupo que as exerça sobre outros. Elas não são colocadas em movimento como resultado de arranjos políticos ocultos; elas não emanam de algum centro, como o Estado (nem mesmo o absolutista). Ao contrário, tais forças estão distribuídas difusamente por todo tecido social. (p.61).

No campo da Educação brasileira, temos muitos exemplos emblemáticos que reforçam as ideias de Foucault, como as próprias Leis acima citadas que ficaram no campo das interpretações, abrindo brechas para retrocederem de acordo com interesses e princípios contrários que alojaram tais Leis. Ou seja, só a Educação atingindo o tecido social, especialmente, a maioria que são excluídas, é a saída.

Em sua proposta pedagógica, Arroyo (2012) entende que uma Educação, a qual pretende ser inclusiva, busca fazer perceber aquele que é considerado marginalizado - um ser diferente ou diverso - pelo ângulo positivo, pelo prisma do direito e da justiça social coletiva. Nesse sentido, torna-se imprescindível a compreensão dos conhecimentos que atualmente medeiam o cotidiano escolar, visto que sua seleção vem adequar-se a uma visão de mundo que estratifica e exclui socialmente, ou seja, contribui para aumentar a marginalidade.

Por isso, no pensar de Gohn (2001), hodiernamente, a ideia de Educação pertinente é a que está no contexto da diversidade; é a que pleiteia a superação da miséria do povo, que luta pela promoção dos excluídos numa perspectiva de uma sociedade mais justa e com equidade, que se empenha para que aconteça melhor distribuição de renda, direito coletivo e justiça, ressaltando que "no mais das vezes a questão da igualdade é tratada sob o vértice da máxima aristotélica que preconiza o tratamento igual aos iguais e desigual aos desiguais, na medida dessa desigualdade" (ARAÚJO, 2006, p. 131).

Tal forma de compreender a Educação se norteia por princípios, tais como o respeito às diferenças, o reconhecimento (NEVES, 2005), o diálogo, a cultura da paz, que não 
significa ausência de conflito; a empatia, que não é se sentir no lugar do outro, mas sim sentir com o outro (NASCIMENTO, 2014); que parte da ação educativa interlmultiltransdisciplinar, que se alicerça na pluralidade, democratização, subjetividade e singularidade (REY, 2005), ao ponto de haver uma transformação pessoal e social do sujeito, fazendo-o passar de ser considerado inexistente para existente (ARROYO, 2012).

É um caminho possível e exímio para possibilitar "a conquista da cidadania aos sujeitos ao trazer a oportunidade de um processo de conscientização de seu contexto sócio, histórico, cultural, onde o transforma em um cidadão participativo e crítico" (GOHN, 2015, p. 11). A escola pode, pela única maneira concebível, a democrática, contribuir para a formação que, realmente, liberte, já que ela consegue melhor do que nunca dissimular a função que desempenha.

Uma das preocupações muito presentes nos textos de Gohn é a distinção entre Educação Formal, Informal e Não-Formal. A Educação Formal refere-se à que se tem nas escolas; a Infomal, é a que os indivíduos aprendem durante seu processo de socialização - na família, bairro, clube, amigos etc.; e a Não-Formal, é aquela que se aprende "no mundo da vida", por meio dos processos de compartilhamento de experiências, principalmente em espaços e ações coletivas cotidianos.

Na Educação Formal, o professor é uma peça chave, tendo por espaço de educação a escolalinstituição e a regulamentação por lei. Na Educação Informal, por sua vez, os professores são os chamados "chegados" e tem por espaço de educação a cidade, nacionalidade, etnia, religião, casa onde se mora etc. E, na Educação Não-Formal, o grande educador é o "outro", aquele com quem interagimos ou nos integramos; o espaço de educação localiza-se em territórios que acompanham as trajetórias de vida dos grupos e indivíduos, fora das escolas, em locais informais, locais onde há processos interativos intencionais. O que se destaca na Educação Formal é a norma; na Informal, a espontaneidade; na Não-Formal, a intencionalidadelliberdade, escolha, querer, vontade, participação (GOHN, 2006).

Por isso, na ótica de Gohn, a Educação Não-Formal é boa, pois possibilita aos sujeitos tornarem-se cidadãos do mundo, no mundo, por meio de um processo educativo que não é preestabelecido, mas engendrado no próprio processo, de forma interativa, uma vez que a finalidade é atingir o sujeito que participa do processo, e não os interesses e necessidades de quem está externo, como a questão capitalista.

Vale ainda destacar, que na Educação Não-Formal as relações não acontecem de maneira hierarquizada, mas, na equidade e justiça social, preparando o sujeito para o exercício 
da cidadania, por meio de formação política e sociocultural, aprimorando a civilidade e combatendo o egoísmolindividualismo. Na Educação Não-Formal, a metodologia atua sobre aspectos subjetivos do grupo; trabalha e forma a cultura política de um grupo; desenvolve laços de pertencimento; ajuda a construção da identidade coletiva do grupo; colabora para o desenvolvimento da autoestima e do empoderamento do grupo; fundamenta-se no critério da solidariedade e identificação de interesses comuns e é parte do processo de construção da cidadania coletiva e pública do grupo. Neste sentido, difere da Formal, que se organiza por séries/ idade/conteúdos.

Ainda sobre a Educação Não-Formal, o método nasce a partir de problematização da vida cotidiana; os conteúdos emergem a partir dos temas que se colocam como necessidades, carências, desafios, obstáculos ou ações empreendedoras a serem realizadas; os conteúdos não são dados a priori, mas são construídos a partir do processo, baseando-se no sentido e significado dado às ações humanas; na existência da motivação das pessoas que participam; evita meios burocráticos; é dinâmica; busca a formação integral dos indivíduos. Entretanto, Gohn deixa claro que a Educação Não-Formal está centrada no ser humano como um todo, enquanto cidadão do mundo, e não está para combater e nem substituir a Formal e nem a Informal, mas pode ser sumarizada em uma Educação para cidadania, justiça social, direitos (humanos, sociais, políticos, culturais, etc.), liberdade, igualdade, democracia, contra discriminação, pelo exercício da cultura, e para a manifestação das diferenças culturais (GOHN, 2006).

Dentro dessa perspectiva e tendo elementos que se interconectam e possuem consonância com a Educação Não-Formal, Mantoan (2015) apresenta um conceito de Educação Inclusiva como uma modalidade educacional que não se pauta por um estar junto, num aglomerado de pessoas que não se conhecem, mas numa ação educativa que interaja e esteja com o outro, num respeito incondicional por esse outro, numa perspectiva diferenciada. Propõe que, em tempos de mudanças, tem-se que preparar para uma diversidade, pois o novo chegou com o seu ritmo e desafios. O desafio da inclusão foca na quebra de paradigmas. Muda-se, assim, o paradigma de se nortear pelo que é padrão, homogêneo, igual, para o foco da heterogeneidade, para o valor da diferença, da diversidade, do democrático, das diversas experiências. É mais que tolerar e respeitar, é buscar compreender. É incentivar e criar espaços de convivência, de cidadania. Acabar com a comparação e entender que todos precisam conviver, dialogar e interagir. Pois bem, tais reflexões, que provocam grande 
celeuma no contexto da educação brasileira, precisam ser intensamente discutidas e resignificadas, se se acredita na possibilidade de mudança.

Na perspectiva de Lopes (2011), a ideia de uma sociedade que seja inclusiva está fundamentada em uma filosofia que reconhece e valoriza a diversidade. A autora aponta para o perigo de regras definidas por alguém que não sabe o que é ter uma deficiência e, por conseguinte, promove relações engessadas ao ponto das ações serem mais assistencialistas que efetivas e transformadoras. Nesse sentido, Foucault enfatiza que a docilização do corpo é bem mais conveniente do que o "terror", porém, para compreendê-lo em sua positividade, ou seja, compreendê-lo naquilo que ele é capaz de produzir, em termos de efeitos, faz-se necessário acreditar que os conflitos podem ser o meio para atingir o fim. (VEIGA NETO, 2007).

Diante disso, a defesa de Arroyo (2012) é lutar por uma prática educativa que diz aos "Outros sujeitos", por exemplo - as crianças e adolescentes que estão em uma situação de vulnerabilidade social - que eles existem, estão aí, para que possamos realizar uma Educação que não seja um favor, mas uma forma de lutar com eles a fim de que se tornem o que sempre foram e são: sujeitos de direitos e não a ser "salvos". Assim, a compreensão de Educação Inclusiva que a presente pesquisa persegue pode ser resumida nos dizeres de Cavalcanti e Gangorra:

\begin{abstract}
A Educação Inclusiva busca abranger todos com equidade e igualdade de oportunidades. A proposta de Educação Inclusiva vem reconhecer os movimentos ao longo do tempo e assegurar aos cidadãos a possibilidade de aprender e de conviver, de forma correta e respeitosa, em uma sociedade diversificada. Esse tipo de convivência permite às pessoas com necessidades educacionais especiais maiores possibilidades de se desenvolver acadêmica e socialmente. Permite, também, uma prática saudável para todos, espaço de convivência, democracia, respeito e valorização do outro. (2013, p. 69-70).
\end{abstract}

Por isso, após discutir-se, com a contribuição de alguns autores, de modo sumário, os conceitos de Educação, Educação Não-Formal e Educação Inclusiva, apresenta-se a seguir a pesquisa acerca da Educação Inclusiva a partir das experiências fornecidas pelas Narrativas Autobiográficas dos egressos do IPLC selecionados para a pesquisa.

\title{
A Educação Inclusiva concebida pela experiência
}

O que esperar de uma criança desamparada, vítima de violência, mergulhada em toda sorte de desamparo pela sociedade, sendo tratada na escola "regular" como "iguais", em um 
processo dito democrático, já que todos devem aprender as mesmas coisas, terem acesso às mesmas informações, ainda que possam necessitar de outros conhecimentos, de apoio e acolhimento, e não são considerados por essa escola com aquilo que trazem, como percebemos no depoimento do EN1?

Quando eu vim estudar aqui no Instituto aos sete anos de idade, o meu pai trabalhava como vigia nesta época, então meu pai veio a falecer, era ele que provia, que mantinha a casa. Meu pai veio a falecer, foi assassinado. Então minha mãe não sabe ler nem escrever, analfabeta e nunca tinha se visto em uma situação como essa, não tinha nenhuma renda para manter os quatro filhos. Tínhamos fome, fome mesmo. (respira, chora e repete)... fome mesmo [...] então, foi assim que eu ingressei junto com meus irmãos no Instituto. Então, a partir daí, a partir das aulas de formação, a partir do acolhimento que eu tive aqui junto com os meus irmãos, então eu pude ter uma visão diferente, e não assim de não propagar aquilo que a minha família tinha para me oferecer, porque minha mãe analfabeta, ela não poderia ir além daquilo que ela tem e os meus irmãos também. [...]

A partir desta fala, pode-se inferir que uma Educação, sobretudo se pretende ser inclusiva, deve reforçar e despertar na CASVS o que canta Natiruts na música: "liberdade pra dentro da cabeça", através do acolhimento e da formação, levando o sujeito a entender que ele pode, tem potencial, que ele não é sua situação imposta pela sociedade, cultura ou situação familiar. O relevante é perceber que não existe determinismo, mas que "cada um carrega o dom de ser capaz e ser feliz", como canta Almir Sater, na música "tocando em frente", que um educador, quando perspectiva usar uma modalidade inclusiva, especialmente, quando se trata de uma CASVS, deve utilizar o diálogo, o acolhimento, afetividade, lutar para matar a "fome" em muitos sentidos, a dúvida com o propósito de melhorar as pessoas e o mundo, como afirma Nascimento:

[...] podia contar com a abertura intelectual dos jovens para a recepção e a interação da aprendizagem do conhecimento, realizando-o com empatia, afetividade e postulando temáticas de interesses humanos. Assim, orientando-se uma atitude crítica perante o mundo, mantendo-se o 'espanto' e a 'admiração' enquanto estratégias de descobertas e intervenções, Sócrates e seus parceiros jovens iam dando sentido à vida e pondo-a em constante exames. ( 2014, p. 17)

Partindo do pressuposto de que toda situação de pobreza socioeconômica é excludente, fica ainda mais difícil de serem analisadas as outras dimensões de pobreza, ou seja, o desamparo psicológico e um modelo de Estado que permite falhas gritantes do judiciário, que não deve ser considerado menos importante. Será que o modelo de escola regular daria conta de trabalhar essas várias vítimas, que não são poucas, valorizando essas várias dimensões de 
um mesmo sujeito? Será que situações como a do EN1 não pode justificar a evasão na escola? Igualmente, a escola regular consegue promover uma Educação Inclusiva com CASVS?

São questões que instigam o entendimento de que a existência de projetos como o do Instituo Pe. Luis Cecchin podem atenuar a desigualdade e a exclusão social. A fala de EN1 destaca que não são os conceitos, didáticas ou estratégias pedagógicas que podem resolver a situação de CASVS, mas a questão principal é colocá-los como protagonistas da sua história, por meio do acolhimento e formação humana.

A preocupação em conhecer a realidade do educando, sua história de vida, sua singularidade, discuti-la, e, na medida do possível, desconstruir com atividades concretas seus sentimentos de revolta e desespero; realizar o seu reconhecimento como pensa Neves (2005); permitir que possa ser protagonista da sua formação com foco na "Liberdade e autonomia", como advoga Nascimento (2014), pode ser o meio conveniente para manter o sujeito motivado em buscar condições de se libertar dos limites que lhe impedem de caminhar com dignidade elou ter um êxito social. Continua EN7:

Então, aqui no Instituto, eu tive várias possibilidades e vários incentivos de buscar algo para minha vida, uma profissionalização, um trabalho, algo que no futuro eu possa me manter, manter minha família, como também me tornar uma pessoa consciente dos meus direitos e deveres diante da sociedade.

Sobre a fala acima, fica claro o anseio de EN1 e a motivação em buscar a dignidade elou êxito social que todo ser humano deve ter oportunidade e, ainda, seu sentimento de gratidão em poder estender os benefícios a toda sua família. Nessa perspectiva, fica evidenciada a categoria inclusão social na escola, que sobressai na sua fala, nos sentimentos de satisfação, doação, missão e consciência de sua cidadania.

Continuamente há comprovações de implicações positivas, inclusive no sentido da formação de vínculos de gratidão que EN2 considera positivo, quando declara:

Então, o Instituto através de todas as formações que eu tive enquanto aluna, trouxe esses questionamentos para mim, e que hoje, graças a Deus, como colaboradora, há 12 anos que eu trabalho aqui, eu procuro tanto aprimorar a minha profissão, que hoje eu sou Assistente Social, mas como também poder retribuir tudo àquilo que eu tive aqui.

Interessante notar que a formação no Instituto Padre Luis Cecchin (IPLC) não é deslocada da vida da comunidade, mas possui uma continuidade. Percebe-se o sentimento de satisfação em manifestar a trajetória de vida e a oportunidade que se teve ao frequentá-lo, nas narrativas dos egressos. 
São várias as vertentes que surgem quando se procura conhecer experiência exitosa como a do IPLC. A complementariedade em relação à escola, a não formalidade, o acolhimento, os novos princípios e a flexibilidade têm destaque na estrutura funcional desse Instituto, que está voltado, de modo muito especial, a crianças e a adolescentes vulneráveis socialmente, muitas vezes reconhecidos pela comunidade local como sujeitos indisciplinados, com baixa autoestima, desordeiros, como "não tem jeito", marginais, criminosos.

O próprio folder do Instituto relata, primeiramente, que é um trabalho realizado dando relevância ao amor e à fraternidade. No intuito de atender a este princípio, o Instituto toma como Missão Institucional promover crianças, adolescentes, jovens e famílias em situação de vulnerabilidade social oferecendo-lhes assistência, formação humana e espiritualidade, educação e profissionalização, tendo em vista uma consciência crítica da realidade e do valor da pessoa, buscando interferir nas estruturas sociais para o exercício da cidadania.

De modo evidente, vislumbra-se, nos depoimentos dos egressos, que no IPLC eles passaram pela valorização de si, decorrente de referências, de ações e de práticas pedagógicas que garantiram espaço para a construção valorativa dos educandos, em relação a si e de como outros o percebem positivamente, sobretudo, pela pessoa do fundador Pe. Luis Cecchin, como bem ilustra EN3:

\begin{abstract}
A nossa vida, ela era um pouco complicada, meu pai era alcoólatra, minha mãe era doméstica. Vivia trabalhando na casa dos outros pra ganhar alguma coisa pra trazer pra casa. Sete irmãos, numa família de sete irmãos, nós tínhamos dias que não tínhamos o necessário para comer. [...] a formação humana, cristã, religiosa que era dada aqui no Instituto tanto pelo Pe. Luis como pelas freiras Franciscanas Maristelas do Brasil. Essa é a influência maior. Foi a formação, o acolhimento, a formação. Eu aprendi ser homem aqui dentro.
\end{abstract}

Tendo em vista a necessidade de fazer valer os direitos e os deveres das CASVS que ingressam no Instituto, e, ainda, a responsabilidade em garantir uma formação integral, podese perceber a determinação da equipe em planejar ações que envolvam, na medida do possível, a família e a comunidade como coparticipantes da trajetória formativa delas, evitando caracterizar assistencialismo ou ações paternalistas. Assim sendo, os pais ou responsáveis são convocados a trabalhar, a partir de suas condições (quantidade de horas semanais dependerão da situação de cada um), justificado pela responsabilidade que cada um deve ter com sua paternidade ou sua maternidade. Assim, diz EN4:

Aqui, percebíamos claramente o que o fundador Pe. Luis Cechin disse a um pequeno comerciante, quando este deu uma ajuda a uma criança que passou 
pedindo: "não dê o peixe, ensine a pescar". Assim fazia com a gente. A princípio tínhamos comida. Mas, tínhamos que aprender uma profissão. Ir para horta. Aprender a ler e escrever, vinha com o trabalhar a terra. (...) Nossa mãe tinha que vir uma vez da semana para receber formação e dá um expediente ajudando em algumas coisas do Instituto. Como também o Padre comprou terra e dava para nossos pais trabalharem. Plantarem milho e feijão para nossa família.

Na fala de EN4 percebe-se a relevância de uma responsabilidade "responsável" de modo comum, bem presente na ótica reflexiva de Lévinas, quando retoma uma frase de Crime e Castigo, de Dostoievski, ao afirmar que "cada um de nós é responsável diante de todos por todos e por tudo, e eu mais que todos"(LÉVINAS, 2002, pp. 145 e 148). Mais uma vez volta a ideia de não "se dá o peixe, mas de se ensinar a pescar", mas, que, o outro sem o peixe não pode nem pescar, pois, não está alimentado. Daí, urge uma ação que brota do se sentir responsável pelo outro levando-o a ter autonomia. Por outro lado, a busca de uma ação educativa que vislumbra o educando não como um subalterno, colonizado, escravo, “coitadinho", na lógica do "padrão de poderlsaber, das epistemologias de educação trazidas de fora (...) para outras pedagogias inventadas, outras formas de pensá-los e de pensar a educação" (ARROYO, 2012, p. 11), faz toda uma diferença na vida de uma pessoa humana, especialmente, quando tal pessoa é uma CASVS, cujo escopo deve ser que o sujeito educando passe de uma situação que tinha muito para ser um problema pessoal e social para um êxito social Nesse mesmo sentido atesta EN1:

Pra mim, inclusive pros outros que aqui passaram a mesma formação que eu tive todos os outros tiveram. Porém, hoje se você olhar pra trás eu também poderia ter sido assassinado, ter entrado no mundo do crime, tá preso. Eu tenho muitos amigos daquele período que estão assim, outros tão bem sucedidos, porém a formação e a persistência de Pe. Luís e das freiras que estavam sempre incentivando a gente a não desistir de sermos alguma coisa na vida. Até porque no passado, mais do que hoje, todas as crianças que aqui foram atendidas, como eu, vivíamos no estado de risco, de vulnerabilidade, de risco social. Se esta casa não existisse, se o Pe. Luis não tivesse tomado essa iniciativa, nós iríamos ter uma geração de vagabundos, de assassinos, de ladrões, de gente morta, então, nós vivíamos na pobreza mesmo. Era pobreza, fome, pobreza de espírito, e aqui nós recebemos formação religiosa, humana, cristã.

O depoimento acima apontou a relevância do trabalho formativo executado pelo Instituto, que superou a impregnação de uma realidade cruel de fome e de desamparo nas mais diversas dimensões desses CASVS que, se não tivessem tido a oportunidade de participar desse Instituto, poderiam não ter o direito mínimo de se tornarem cidadãos. De fato, encontra-se na ação educativa do Instituto adequação e justificativa de hipóteses de vários 
teóricos que refletem sobre a Educação Inclusiva. Esta não deve ser uma muleta para o educando com necessidades especiais, como as CASVS, mas, como propõe Bomfim (2014), a Educação deve ter ações alicerçadas na Ética - fazer ao outro o que quer que o outro faça a si, como cuidado e solidariedade universal; na Esperança - não é mera expectativa, mas virtude de força intrínseca que executa um objetivo que busca tornar o desejo possível e não na Utopia - não está no campo do impossível, mas, conquanto tenha percalços, é possível de ser realizado, por meio da interação, negociação, prática de empoderamento e prática empreendedora. Chama atenção o relato de EN5, quando afirma:

Pe. Luiz, assim, é uma pessoa que não se consegue arrumar um adjetivo que classifique a pessoa dele, era um homem bondoso, muito determinado, missionário, mas também uma pessoa bastante exigente naquilo que buscava dos seus alunos. Acolhia crianças abandonadas de ruas, nas ruas, com a intenção de vê-las em outra situação de vida que não fosse aquela que a encontrou.

A primeira questão que salta aos olhos nessa fala é o testemunho de vida de Pe. Luís como fator norteador. É como se sua presença na vida dessas CASVS possuísse, em si mesmo, valor formador, capaz de garantir conhecimentos fundamentais para formação integral e para a cidadania, ou seja, seu testemunho valendo mais do que suas palavras. Isto atenta para o fato de que uma Educação Inclusiva tem mais eficácia quando os educadores são também formadores com a sua própria vida, são capazes de agir com coerência humanizadora.

Ao verificar a fala de EN4, tem-se a sensação de que uma ação educativa, seja parte de uma instituição escolar regular ou não, que tem como público CASVS, pode atingir melhor o seu êxito quando é consolidada na busca sincera da transformação social e pessoal dos sujeitos, no ver o outro pelo outro, e não por interesses pessoais, não apenas no simplesmente fazer por fazer:

No Centro de Formação a gente recebia os cuidados, cuidados de que... cuidados de alimentação, os cuidados de higiene, cuidado de tarefa escolar, tudo assim. A gente como criança, mas tudo novo pra gente, para meus irmão que nós não tínhamos. Né que meus pais fossem ruins nesse sentido, é que não tinha mesmo essa preocupação, e o Centro de Formação ajudou a gente nisso aí. Além dessas necessidades, o Centro de Formação, através de Pe. Luis que era pessoa responsável, ele se preocupava muito com essa parte da formação da gente.

A fala de EN4 evidencia demanda "particularista" de grupo de crianças e jovens excluídos que precisam das condições mínimas para garantir o desenvolvimento de suas faculdades cognitivas, afetivas e físicas. Por isso, o que parece relevante é que o Instituto 
preocupa-se com o sujeito nas suas várias dimensões, apontando como meta a formação do cidadão integral, ao chamar a atenção com ações voltadas para uma Educação que atenda efetivamente as necessidades mais gerais da pessoa humana, preenchendo lacunas, infelizmente, deixadas pela família. EN5, situando sua realidade, bem comum na sociedade, diz:

Eu me enquadraria, eu e meus irmãos, naquele momento, naquela época, nós nos enquadrávamos perfeitamente nesse quadro de vulnerabilidade, de risco. Risco de ficar sem estudar, risco de ficar ocioso. Meus pais não tinham vícios, nem meu pai, nem minha mãe, não tinham vícios, mas a gente fica sem... é como se fosse um pouquinho sem rumo, é um risco que a gente corre também. É risco que às vezes não é tão visível, mas de você não ter alguém que lhe dê a direção, que lhe dê um rumo, uma orientação. Aqui me fizeram ser gente. Ter um diploma. Um nome. Uma profissão. E, eu busquei ir além. Hoje, sei quem sou e tenho uma graduação.

O que foi dito acima tem muita consonância com o que Arendt (1978) propõe: Educação como nascimento, com a qual o mundo novo deve ser colocado no mundo velho, num processo dialogal e libertador necessários ao ponto de fazer com que o sujeito educando possa adquirir uma liberdade tal que tenha a capacidade e condição, concomitantes, de nem estar sujeito a comandante, seja por necessidades da vida, nem também passe a comandar (ARENDT, 1997).

Também parece ser relevante o que Freire (1979) pensa na obra Educação e Mudança. Ele propugna que o homem somente é capaz quando, em sua reflexão-ação, poder "distanciarse" de sua realidade para, com ela, ficar capaz de observá-la para, objetivando-a, transformála e, transformando, ver-se transformado pela sua própria criação, ao ponto de ser um sujeito comprometido com sua realidade. Tal compromisso só é verdadeiro quando está ligado à solidariedade, que não significa compromisso em dar bens materiais, mas em estar companheiro de pessoas, determinadas pela sociedade como objetos de manobras, como coisas, como alienadas.

O papel do comprometido é superar tal realidade por meio da criatividade, da percepção da condição humana como inacabada e imperfeita, pela comunhão com outros homens, tendo como meta o saber, que indica ignorância, abertura para a busca do saber tendo como intermediário amor, como aquele que é combustível ao entendimento e esperança, como o que motiva a procura, por meio da necessidade da estimulação da consciência reflexiva no sujeito, para que este reflita sobre sua própria realidade, conseguindo assim que as relações dele sejam reflexivas, consequentes, transcendentes e temporais. Nesse contexto, reflexiva significa contemplar sua realidade, transcendendo-a, isto é, por sua reflexão conseguir 
projetar um futuro de acordo com seus desejos, tornando assim sua relação também consequente, e temporal por agir, que significa perceber-se e fazer-se em seu tempo, um ser social e histórico.

Para tal fim, a proposta de Freire (1979), quando não recomenda a Educação "bancária", quer ver no outro um ser "oco", um depósito de conhecimento, um aderir à mudança que ocorre no sentido verdadeiro da humanização do homem, por meio do diálogo, de um método ativo, crítico e criticista; do elemento amor, como sinônimo de confiança, a consciência de que ninguém educa ninguém, mas também não nos educamos sozinhos. Por isso, deve-se vincular a teoria à prática de educar o homem, conhecendo-o e lutando para que ele se encontre. Daí um dos papéis do educador é mostrar e colocar outras condições para o homem, a fim de que ele possa superar suas condições estáticas ou paralisantes. Neste sentido, parece ser pertinente o pensamento de Covey acerca da responsabilidade, que significa, "habilidade para escolher sua resposta" (2003, p. 89), encontrar seu destino, construir a sua história.

Quão relevante se faz, quando se percebe que um sujeito pode mudar sua realidade excludente, de vulnerabilidade social, de precariedade e de inexistência social, não por meio de um acolhimento qualquer, mas de um olhar nos olhos, percebê-lo de verdade, afagá-lo sem perder a posição do limite, numa postura de formar e cuidar o homem integral, numa ação imbuída de um altruísmo alicerçado num cuidado incondicional ao outro pelo outro, (LÉVINAS, 1982). Busca-se praticar palavras do líder maior da Igreja Católica, Jesus Cristo, que pedia o "cuidado ao órfão e à viúva", "vestir o nu, dar de comer a quem tem fome"; que "não existe maior amor do que este: dar a vida por seus amigos" e a consciência de que "por meio disso saberão todos que sois meus discípulos, se tiverdes amor entre vós”3 ${ }^{3}$. Assim, era o agir tanto do fundador do Instituto como daqueles que ali trabalhavam com as CASVS, como diz o egresso EN6:

Ele (Pe. Luis Cechin) tinha um tratamento com a gente diferenciado. Ele era diferenciado. Sua bondade, que só podia vir do amor a Jesus Cristo, do seu desejo de servi-lo e praticar os seus ensinamentos. Assim, ele nos olhava nos olhos. Nos enxergava. Nos via (neste momento o entrevistado derrama lágrimas nos olhos). Nos tratava com um carinho e amor que nem nossa mãe nos tratava. O seu abraço, o seu falar, eram diferentes. Ele só tinha amor no coração. Mas, não só ele, toda a equipe do Instituto. Era duro. Firme. Tinha as regras. Mas, me sentia visto. Cuidado. Lembrado. Ele queria nos educar. Nos formar como homem, como um bom homem. Homem inteiro, entende? Como cidadão de verdade.

\footnotetext{
${ }^{3}$ Frases citadas da Bíblia. Cf, Mateus 25, 35; João 15,15; João 13, 35, respectivamente, na Bíblia Jerusalém, 10 impressão, 2001.
} 
Entende-se o quanto parece pertinente o que conclama Arroyo (2012), quando aponta que é preciso ter Outra Pedagogia para o Outro Sujeito, que é absolutamente Outro, um ser humano, e não um metafísico e economicamente sob o nome de "pobre", numa noção genérica do termo. É vítima, porque foi produzido como inexistente, subalterno, desumanizado, segregado e discriminado como inferior porque diferente, pela precarização e negação das condições materiais de seu viver, pela expropriação das terras, territórios, teto, espaços, até de conhecimento, pela destruição das culturas, saberes, identidades e memórias, pelo decreto que o coloca como sem cidadania, direito a ter direito - terra, espaço (de existência, valores, culturas, no fazer da lei e das políticas públicas), trabalho, vida, de humanidade. Na ideia de Arroyo (2012), uma possível saída para esse "Outro" é a de "Outras Pedagogias" que se confeccionam e confirmam pela rejeição às pedagogias gestadas no padrão de poder, saber, dominação, colonização, homogeneizador, eurocêntrico, desenraizador, desterrorializador, subalternizador, desumanizador, criminalizador, escravocrata, precarizador, segregador, culturicida.

Os elementos essenciais das "Outras Pedagogias" devem ser a resistência, afirmação, participação, luta, direito coletivo, justiça coletiva, diversidade, valor do diferente, resignificador, territorizador, libertador, emancipador, repolitizador, humanizador. Mais que isso, a Pedagogia do amor, ágape, no sentido grego, conforme aponta Rossi (2015), o amor que se doa, o amor incondicional, o amor que se entrega, mas, também, a Pedagogia do reconhecimento, do empoderamento, da singularidade, da formação do homem e sua realização no mundo, do Cuidado como pensa Boff (2005). Pelo cuidado se chega a uma sintonia com as coisas, a uma convivência amorosa. Cuidado é pathos, introspecção, emoção, um sentimento que permanece indelével. Boff chama o Cuidado como categoria matricial, que é capaz de inspirar um novo acordo entre os seres humanos e uma nova relação para com a natureza. O Cuidado leva o homem a defini-lo como um "ser-de-cuidado".

Sendo assim, cuidado está na constituição do homem, no seu ser, na sua ontologia, ao ponto de não poder ser se não for cuidado, chegando a afirmar: "sem o cuidado o homem e a mulher não podem ser chamados de ser humano" (BOFF, 2005, p. 1). Portanto, com tal Pedagogia, deve-se vencer o que o Papa Francisco tem denunciado de modo veemente pelo mundo, a "globalização e cultura da indiferença", quando escreve:

[...] quase sem nos dar conta, tornamo-nos incapazes de nos compadecer ao ouvir os clamores alheios, já não choramos à vista do drama dos outros, nem nos interessa por cuidar deles, como se tudo fosse uma responsabilidade de 
outrem, que não nos incumbe. A cultura do bem-estar nos anestesia, a ponto de perdermos a serenidade se o mercado oferece algo que ainda não compramos, enquanto todas estas vidas ceifadas por falta de possibilidades nos parecem um mero espetáculo que não nos incomoda de forma alguma" (FRANCISCO, 2013, pp. 45-46)

$\mathrm{Na}$ contramão dessa sociedade que globaliza a diferença, encontra-se a fala do egresso EN6, as atitudes do fundador e de outros membros da equipe. Assim, uma Educação que pretende ser para todos, inclusiva, sobretudo quando o público é CASVS, deve ver e rever a ideia do pensamento autoritário, totalitário, detentor do poder pedagógico; e, buscar levar em conta a história pessoal, a singularidade, subjetividade de cada educando, a exemplo do que traz a música em Epitáfio cantada pelos Titãs: “queria ter aceitado as pessoas como elas são, cada um sabe a alegria e a dor que traz no coração". É preciso vislumbrar as CASVS não como um problema, mas como sujeitos que estão com um problema. Tratá-los, como propugna Matos (2014), não como "cristalizados", mas como alguém que encontre "conexões|significados de vida", como "interlocutores válidos", por meio de um "educar para paz", que enxerga o conflito pelo lado positivo, vendo-o pelo prisma do diálogo, respeito e compromisso.

No pensamento de Matos (2014), educar para paz é o exercício metodológico do diálogo, do cuidar de si e do outro, como se fosse uma "razão cordial" que faz com que haja reconexão com tudo e com todos, sentimentos, emoções, valores, afetividade, amorosidade, acolhimento, respeito e compromisso como elementos possíveis da paz e da aprendizagem, da formação e educação humanas. Educar para paz é levar o sujeito a refletir sobre sua realidade, buscar uma cidadania crítica e autônoma, com práticas que valorizem e respeitem as diferenças, sobretudo, sem taxá-los como aqueles que trazem "risco social", quando é a própria sociedade que os exclui e marginaliza. Educar para paz é evitar ações repressoras ao invés do diálogo, este entendido como capacidade de negociação.

Dito de outra forma, corresponde a habilidades em resolver conflitos de forma sábia, respeitosa, transformando os espaços de Educação em espaços proativos; é a ideia de coeducação, compartilhamento de ações e experiências; é buscar políticas preventivas que garantam para eles o bem-estar e a convivência solidária; é criar laços e espaços, onde possam falar de si, da família, do que fazem de proveitoso ou não, do que produz vida melhor. Assim, ancorada em Lacan, Matos advoga que um sintoma, como a vulnerabilidade social das crianças e dos adolescentes, é uma oportunidade para se fazer amado, seja em relação ao semelhante ou ao social. Por isso, os conflitos não se resolvem nem com punições e nem 
polícia, mas “o diálogo com alunos e a comunidade é a forma mais efetiva de construir a paz no espaço escolar, considerando as dimensões ética e afetiva”. (MATOS, 2014, p. 183)

\section{Para não concluir}

Entremeado e invólucro na presente pesquisa, infere-se o quanto temos a fazer em relação às CASVS, pois ficou claro que a vulnerabilidade social de algumas crianças e adolescentes persistem apesar de todo um esforço, notadamente advindos de políticas públicas, quanto de iniciativas institucionais e individuais, filantrópicas, não governamentais etc., o que reflete a necessidade em intensificar os investimentos nesse sentido. A realidade de CASVS, indiscutivelmente, é desafiadora, porém instigante no sentido de refletir sobre excluídos, que na sua maioria está tal público, e pensá-los como algo que leva a inquietude e que convida à responsabilidade e compromisso, em participar do processo de mudança.

Isto exige uma abertura para pensar o que somos, reconhecer a realidade do outro no nosso caminhar, estabelecer pontes para que seja possível alcançar um espaço comum, onde as diferenças possam significar pluralidade e não desigualdade e/ou exclusão, muito especialmente, repensar a funcionalidade da escola que temos e o tipo de Educação que estamos perpetrando. A confiança no outro nem sempre é algo pacífico. Isso se torna mais visível quando se trata de seres humanos que são permeados de marcas negativas, com traumas, violências, prostituição forçada etc., que, naturalmente, precisam de um tratamento diferenciado, como se pode deduzir a partir das narrativas autobiográficas das análises dos dados fornecidos pelo público alvo da pesquisa. Nesse sentido, conclui-se, ainda, que a omissão e/ou o silêncio que existe nos Currículos Oficiais é excludente, pois não valoriza situações específicas, não levam em conta a singularidade, a subjetividade, o direito a ter direito, como a que abordamos neste artigo.

Portanto, tentou-se contribuir para reflexões acerca da Educação Inclusiva, Educação Não-Formal, com foco em CASVS, numa busca que parece urgir atualmente em nosso país, no intuito de ser mais um "soldado" nessa que deve ser uma "cruzada" do presente, qual seja, a luta pela erradicação daquela que precisa ser erradicada: a exclusão social, sobretudo de CASVS, caso se almeje ter uma sociedade capaz de acolher a todos, devolvendo àqueles que são tratados como inexistentes a existência, a dignidade, a cidadania, o direito de ter direito, numa visão holística junguiana, no sentido que um o sujeito não o é enquanto não passar pelo processo de individuação, isto é, aparte do todo, mas, também, não o será enquanto não 
estiver visceralmente ligado ao mesmo todo. Sendo assim, todo e um não se confundem, mas, concomitantemente, não o são sem um supor o outro. (JUNG, 2005). Diante do que aqui, discutimos, conclui-se que não se chegou a uma conclusão, pois, longe de se pretender ser um ponto final, a presente reflexão quer ser mais um pingo de água nesse oceano da Educação, principalmente, no que se tange a CASVS, ao ponto de dizer: a presente pesquisa pretende ser um "fim" de um começo e um começo sem fim.

\section{REFERÊNCIAS}

ALBUQUERQUE, Maria Jaques de. Retrospectiva histórica da didática e o educador. In: Revista Educação: Teorias e Práticas, Universidade Católica de Pernambuco, ano 2, $\mathrm{n}^{\circ}$ 2, p. 38-60, dez, 2002

ANDRÉ, M. Pesquisa em educação: trajetórias e desafios contemporâneos. In: IBIAPINA, M. I. L. de M.; Carvalho, M. V. C. de. Educação, práticas socioeducativas e formação de professores. Teresina: EDUFPI, 2009.

ARAÚJO, Luiz Alberto David. Direito constitucional: princípio da isonomia e a constatação da discriminação positiva. São Paulo: Saraiva, 2006.

ARENDT, Hannah. A condição humana. Universitária: Forenze, 1997.

ARENDT, Hannah. Entre o passado e o futuro. São Paulo-SP: Perspectiva, 1978.

ARROYO, Miguel G. A infância deixada na estrada: buscá-la onde ela ficou. Cad. Cedes, Campinas, v. 35, n. Especial, p. 335-341, out., 2015.

ARROYO, Miguel G. Outros sujeitos, outras pedagogias. Petrópolis-RJ: Vozes, 2012.

BÍBLIA JESURALÉM, São Paulo: Paulus, 2005.

BOFF, Leonardo. O cuidado essencial: princípio de um novo ethos. Inclusão Social, v. 1, n. $1,2005$.

BOMFIM, Maria do Carmo Alves do. Pesquisas sobre juventudes: uma das trajetórias do NEPEGECI. In: BOMFIM, Maria do Carmo Alves do; ADAD, Shara Jane Holanda Costa; NASCIMENTO, Adriana Loiola do (Org.). Educação, diversidades e políticas de inclusão: juventudes, cultura de paz e subjetividades. v. II. Teresina: EDUFPI, 2014. p. 16-35.

BRASIL. Constituição (1988). Constituição da República Federativa do Brasil. Brasília, DF: Senado Federal: Centro Gráfico, 1988. 292 p.

BRASIL. Lei de diretrizes e Bases da Educação Nacional, LDB. Lei no 8069/90. Brasília, 20 de Julho de 1996. 
COVEY, Stephen R. Os 7 hábitos das pessoas altamente eficazes. 16. Ed. São Paulo: Nova Cultural, 2003.

DECLARAÇÃO DE SALAMANCA: Sobre princípios, políticas e práticas na área das necessidades educativas especiais. Salamanca-Espanha, 1994.

DELORY-MOMBERGER, C. Biografia e educação: figuras do indivíduo-projeto. Tradução Maria da Conceição Passeggi. Natal, RN: EDURN; São Paulo: Paulus, 2008.

ECA - Estatuto da Criança e do Adolescente. Lei no 8.069, de 13 de julho de 1990.

FFRANCISCO. Exortação Apostólica Evangelii Gaudium. Vaticano, 2013.

FREIRE, Paulo. Educação e mudança. São Paulo-SP: Paz e Terra, 1979.

FREIRE, Paulo. Pedagogia do oprimido. 39. ed. Rio de Janeiro: Paz e Terra, 2004.

GOHN, Maria da Glória (Org.). Educação não-formal no campo das artes. São Paulo: Cortez, 2015.

GOHN, Maria da Glória. Educação não-formal e cultura política: impactos sobre o associativo do terceiro setor. 2.ed. São Paulo: Cortez, 2001.

GOHN, Maria da Glória. Educação não-formal, participação da sociedade civil e estruturas colegiadas nas escolas. Ensaio. Avaliação e Políticas Públicas em Educação, Rio de Janeiro, v. 14, n.50, p. 11-25, 2006.

HATTGE, Morgana Domênica; LOPES, Maura Corcini. A inclusão escolar e o movimento Todos Pela Educação. Revista Educação Especial, v. 28, n. 53, p. 569-582, set./dez. 2015.

JOSSO, M. C. Experiências de vida e formação. Tradução: José Claudino e Júlia Ferreira. São Paulo: Cortez, 2004.

JUNG, C.G. Memória, sonhos e reflexões. Rio de Janeiro-RJ: Nova Fronteira, 2005.

LÉVINAS, Emmanuel. De Deus que vem à idéia. Petrópolis: Vozes, 2002.

LÉVINAS, Emmanuel. Totalidade e infinito. Tradução de José Pinto Ribeiro. Lisboa: Edições 70, 1982.

LOPES, Maura Corcini, HATTGE, Morgana Domência (Org.). Inclusão escolar: conjunto de práticas que governam. 2. ed. Belo Horizonte: Autêntica, 2011.

MANTOAN, Maria Teresa Eglér. Inclusão escolar: o que é? Por quê? Como fazer? São Paulo: Summus Editorial, 2015.

MATOS, Kelma Socorro Lopes de. Educação, diversidades e políticas de inclusão: juventudes, culturas de paz e subjetividades. In: Juventudes e cultura de paz: construções possíveis. Vol. 02, Teresina: EDUFPI, 2014 
NASCIMENTO, Romário Ráwlyson Pereira do. Educação, diversidades e políticas de inclusão: juventudes, culturas de paz e subjetividades. In: Mudanças comportamentais e ressignificação de valores: discursos de sexualidade e experiências juvenis em Teresina nos anos sessenta e setenta. v. 02, Teresina: EDUFPI, 2014

NEVES, Paulo Sérgio da Costa. Luta anti-racista: entre reconhecimento e redistribuição. Revista Brasileira de Ciências Sociais, São Paulo, v. 20, n.59, p. 81-96, 2005.

NOVOA, A.; FINGER, M. (Org.). O método (auto)biográfico e a formação. Natal, RN: EDUFRN; São Paulo: Paulus, 2010.

PIOVESAN, Flávia. Direitos humanos e o direito constitucional internacional. 14. ed., rev. e atual. São Paulo: Saraiva, 2013.

REY, G. F. L. O valor heurístico da subjetividade na investigação psicológica. In: GONZALEZ REY, F. L. (Org). Subjetividade, complexidade e pesquisa em psicologia. São Paulo: Thompson Learning, 2005.

RIZZINI,Irene. Deserdados da sociedade: os meninos de rua da América Latina. Rio de Janeiro: USU Ed. Universitária, 1995.

ROGRIGUES, Luiz Alberto Ribeiro. Gestão democrática e as políticas gerencialistas nas escolas públicas em Pernambuco. UPE. 2016. Texto Didático.

ROSSI, Marcelo. Ágape. Robert Laffont, 2013.

SILVA, Lígia Maria Portela da. Processos de educar e educar-se em instituição de atendimento a crianças e adolescentes em situação de risco. São Paulo: UFSCar, 2007.

SPINDOLA, Thelma; DA SILVA SANTOS, Rosângela. Trabalhando com a história de vida: percalços de uma pesquisa (dora?). Revista da Escola de Enfermagem da USP, v. 37, n. 2, p. 119-126, 2003.

THIOLLENT, Michel. Metodologia da pesquisa-ação. 8. Ed. São Paulo, 1998.

UNICEF. A infância brasileira nos anos 90. Brasília: UNICEF, 1998.

VEIGA-NETO, Alfredo. Foucault e a Educação. Belo Horizonte: Autêntica, 2007.

\section{$\underline{\text { SOBRE OS AUTORES }}$}

\section{Marcos Lucena da Fonseca}

Doutorando em Ciências da Religião pela Universidade Católica de Pernambuco (UNICAP). Mestre em Educação pela Universidade de Pernambuco (UPE). Licenciado em Filosofia, Graduado em Pedagogia, Bacharel em Teologia. Membro do Grupo de Estudo Formação de Professores. Nazaré da Mata - PE. E-mail: fonsecalucena@ hotmail.com 


\section{Maria do Carmo Barbosa de Melo}

Doutora em Educação pela Universidade do Minho (UMINHO). Professora do Programa de Pós-Graduação em Educação da Universidade de Pernambuco (UPE). Coordenadora da Graduação da UPE, Campus Mata Norte. Coordenadora Geral do PARFOR- UPE. Nazaré da Mata -PE. E-mail: mcbmeloupe@gmail.com

Recebido em: 10 de novembro de 2017 Aprovado em: 07 de maio de 2018

Publicado em: 10 de maio de 2019 